\title{
PRÁTICAS DE MARKETING RELACIONAL EM LOJAS DE GAMES: UM ESTUDO SOBRE A PERCEPÇÃO DOS ALUNOS DE UMA INSTITUIÇÃO FEDERAL
}

\section{RELATIONAL MARKETING PRACTICES IN GAMES STORES: A STUDY ON THE PERCEPTION OF STUDENTS OF A FEDERAL INSTITUTION}

Artur Kuchert ${ }^{1}$ https://orcid.org/0000-0002-2623-2753 Maria de Fátima Fagherazzi Pizzoli2 https://orcid.org/0000-0002-9571-4115

Paula Patrícia Ganzer ${ }^{3}$ https://orcid.org/0000-0003-4006-6517 Rodrigo Dullius ${ }^{4}$ https://orcid.org/0000-0002-4865-8798

Recebido em: 16 mar. 2021 Aceito em: 16 out. 2021

Como citar este artigo: KUCHERTT, A. .; FAGHERAZZI PIZZOLI, M. de F. .; GANZER, P. P.; DULLIUS, R. PRÁTICAS DE MARKETING RELACIONAL EM LOJAS DE GAMES: UM ESTUDO SOBRE A PERCEPÇÃO DOS ALUNOS DE UMA INSTITUIÇÃO FEDERAL. Revista Visão: Gestão Organizacional, Caçador (SC), Brasil, v. 10, n. 2, p. 93-114, 2021. DOI: 10.33362/visao.v10i2.2589. Disponível em: https://periodicos.uniarp.edu.br/index.php/visao/article/view/2589.

Resumo: A pesquisa apresenta um estudo acerca da percepção dos alunos de uma Instituição Federal de ensino sobre as práticas de marketing de relacionamento adotadas por varejistas de jogos eletrônicos. A abrangência do estudo considera o universo de lojas físicas instaladas na cidade de Caxias do Sul - RS, como também lojas que realizam vendas por meio online. 0 procedimento metodológico utilizou abordagem quantitativa, de objetivo descritivo, como procedimento técnico utilizou uma Survey. A amostra foi composta por duzentos e vinte e seis respondentes da pesquisa. Os resultados da pesquisa apontaram que as práticas de marketing relacional são mais percebidas em alunos que efetuam compras em lojas online. Os resultados da pesquisa possibilitaram o levantamento de características do comportamento de compra dos alunos, como as suas categorias de jogos preferidas, plataformas e marcas de console em que jogam habitualmente.

Palavras-Chave: Marketing de relacionamento. Práticas Relacionais. Retenção de clientes.

\footnotetext{
${ }^{1}$ Titulação. Departamento ou curso. Instituição de vínculo. E-mail: email@email.com.br.

2 Mestre em Administração pela Universidade Federal do Rio Grande do Sul, Docente do Instituto Federal de Educação, Ciência e Tecnologia do Rio Grande do Sul. E-mail: maria.pizzoli@caxias.ifrs.edu.br.

${ }^{3}$ Doutorado em Administração pela Universidade de Caxias do Sul. Professora Visitante do Instituto Federal de Educação, Ciência e Tecnologia do Rio Grande do Sul. E-mail: ganzer.paula@gmail.com.

${ }^{4}$ Doutorado em Educação pela Universidade do Vale do Rio dos Sinos. Docente do Instituto Federal de Educação, Ciência e Tecnologia do Rio Grande do Sul. E-mail: rodrigo.dullius@caxias.ifrs.edu.br.
} 


\section{Customer Relationship Management.}

Abstract: The research presents a study about the perception of students from a Federal Educational Institution about relationship marketing practices adopted by electronic game retailers. The scope of the study considers the universe of physical stores installed in the city of Caxias do Sul - RS, as well as stores that sell online. The methodological procedure used a quantitative approach, with a descriptive objective, as a technical procedure used a Survey. The sample consisted of two hundred and twenty-six survey respondents. The survey results showed that relational marketing practices are more perceived in students who shop at online stores. The survey results made it possible to survey the characteristics of the students' purchasing behavior, such as their preferred game categories, platforms and console brands in which they habitually play.

Keywords: Relationship marketing. Relational Practices. Customer retention. Customer Relationship Management.

\section{INTRODUÇÃO}

Uma organização possui as mais diversas áreas, e cada uma desempenha sua respectiva e relevante função. A área de marketing possui diversas funções, sendo que uma das principais é a de gerenciar relacionamentos que resultem em retornos a todas as partes interessadas. Para alavancar estes retornos, se faz necessária uma estratégia organizacional voltada para a manutenção de relacionamentos. Destaca-se que os relacionamentos vão além da esfera empresa versus cliente, abrangendo todos os níveis de interação que uma empresa pode ter com as pessoas e organizações, que fazem parte do seu microambiente, desde o fornecedor até o consumidor final.

Quando o cliente pensa em adquirir um produto ou serviço, transcendendo as análises do pensamento lógico, inconscientemente opta pelo produto ou serviço que melhor atende a sua necessidade naquele momento. Mas o que faz com que o consumidor tenha preferência por determinados produtos ou serviços em detrimento de outros? Enquanto empresas, o que as move na direção da compra de insumos de um fornecedor específico muitas vezes abdicando de comprar de um concorrente com preços menores?

O ser humano caminha o tempo todo em direção da satisfação das suas necessidades, e no mundo corporativo isso não é diferente. As empresas também criam laços com aqueles que melhor satisfazem suas necessidades, e justamente esse é o princípio central do marketing relacional. O tema desta pesquisa envolve a área de marketing, com enfoque especial no marketing de relacionamento. Atualmente o país está se recuperando de uma grande recessão econômica. Durante a crise que atingiu o Brasil nos anos recentes, diversas organizações antes tidas como sólidas, viram seus lucros virarem prejuízos, muitas delas acabaram entrando em recuperação judicial, e até mesmo encerrando suas atividades. Quando um país passa por um período turbulento como o Brasil tem passado nos últimos anos, e ocorre a demissão em massa 
de trabalhadores, é comum que se observe a queda nas vendas de artigos vistos como supérfluos ou de lazer, pois em geral a população desempregada acaba direcionando suas finanças para produtos e serviços tidos como de primeira necessidade.

Apesar da crise, um mercado que tem crescido ao longo dos anos é o mercado de games. A indústria de entretenimento bate recordes de faturamento ano após ano, e isso se deve, dentre outros fatores, ao constante aumento do número de consumidores desse tipo de produto. "[...] o mercado de games está em plena expansão no Brasil. De acordo com os dados da Newzoo, em 2017 o número de jogadores era de 66,3 milhões. Em 2018 o número passou para 75,7 milhões de gamers" (DINO, 2018). Se de um lado observa-se o aumento do número de jogadores, de outro constata-se o crescimento do número de desenvolvedores de games. Eliana Russi, diretora da Associação Brasileira dos Desenvolvedores de Jogos Digitais (Abragames), afirmou que em 2008 existiam 43 empresas de games no Brasil, em 2014 esse número subiu para 130, e em 2016 eram aproximadamente 300 empresas desenvolvendo diversos tipos de games. Estes números correspondem a um percentual de crescimento de 600\% entre 2008 a 2016 (SILVEIRA, 2017).

Ao analisar os fatores determinantes para que as empresas se mantenham no mercado, e mesmo prosperem em períodos de crise, observa-se que estas necessitam estar preparadas e estruturadas para enfrentar os diferentes cenários econômicos. O marketing de relacionamento se apresenta como um dos meios que pode ser eleito pelas organizações que desejam atrelar o incremento dos seus resultados à fidelização dos seus clientes e à manutenção dos seus relacionamentos de longo prazo.

Neste contexto, a questão que se pretendeu responder neste estudo foi: Qual a percepção dos gamers do IFRS - Campus Caxias do Sul acerca das práticas relacionais utilizadas pelas lojas de games? A partir da questão de pesquisa, o objetivo foi verificar quais práticas de marketing de relacionamento do segmento varejista de venda de jogos eletrônicos são percebidas pelos alunos do IFRS - Campus Caxias do Sul, considerando o universo de lojas físicas instaladas na cidade de Caxias do Sul, como também lojas que comercializam games online. Como objetivos específicos elencou-se: a) identificar o tipo de loja em que as práticas relacionais são mais percebidas; b) destacar as práticas com maior e menor nível de percepção dos consumidores; c) averiguar as plataformas de jogos com maior incidência; d) elencar as categorias de jogos preferidas pelos estudantes; e) sugerir direcionamentos estratégicos ao segmento varejista de jogos eletrônicos.

Quanto a justificativa, o mercado de entretenimento vem sofrendo significativas transformações ao longo dos anos. Observa-se, por exemplo, que há algumas décadas as locadoras viviam seus anos dourados (BORGES, 2016), onde as fitas de vídeo VHS reinavam soberanas quando a ideia era ver um filme no conforto da residência. Porém, com o passar dos 
anos, novas tecnologias foram sendo lançadas: a fita VHS perdeu espaço para o DVD, que cedeu espaço para o Blu-ray, que por sua vez perdeu espaço para o serviço de streaming prestado por diversas operadoras. Hoje é possível assistir uma gama considerável de filmes, documentários, séries e shows em plataformas inteligentes que apresentam alta tecnologia agregada. Essa instantaneidade de conteúdos certamente não seria possível sem o advento da popularização da internet. Cada vez mais pessoas têm acesso à internet em alta velocidade e, consequentemente, estão acessando com maior frequência os serviços de streaming devido principalmente a sua praticidade e seu preço competitivo (AQUINO, 2019).

O segmento de games está inserido neste mesmo mercado de entretenimento, e assim como ocorreu com a evolução da disponibilização dos filmes, o streaming de jogos já é realidade em alguns países, e está em vias de ser lançado no Brasil (JUNQUEIRA, 2019). Ao que indica, essa inovação tende a mudar significativamente o cenário de consumo e aquisição de games que se observa atualmente. Portanto, a pesquisa se justifica em virtude de ter a finalidade de verificar se o varejo físico e online está preparado para enfrentar as mudanças que estão para ocorrer. Estratégias de marketing de relacionamento surgem como uma ferramenta para que quando o streaming de games for lançado, o varejo se valha de uma relação mais próxima com seus clientes e fornecedores para mitigar a perda de grande percentual de seu market share.

O documento está organizado em seções, na segunda seção aborda o referencial teórico, em que trata do tema de estudo, marketing e suas definições até o marketing de relacionamento, visando embasar o estudo e as análises geradas a partir da pesquisa. $\mathrm{Na}$ terceira seção apresenta a metodologia da pesquisa, em que são descritas as ferramentas de coleta e análise dos resultados. Na quarta seção segue a análise dos dados resultantes da pesquisa e na quinta seção é abordada a conclusão da pesquisa, em que são descritos os resultados a partir dos objetivos, assim como as limitações da pesquisa e sugestões para estudos futuros.

\section{MATERIAL E MÉTODOS}

Esta seção descreve os procedimentos metodológicos adotados na pesquisa, detalhando-se os aspectos de delineamento: método, estratégia, amostra e procedimentos de coleta e análise. Primeiramente, nesta pesquisa optou-se por utilizar um método de pesquisa quantitativo, devido à dimensão da população a ser estudada. De acordo com Costa (2005), quando o conjunto populacional a ser estudado é elevado, as análises quantitativas são as mais adequadas. Mesmo considerando que as pesquisas no campo das ciências sociais aplicadas utilizem em sua maioria a abordagem qualitativa, quando se trata de buscar indicadores e verificar tendências em um grande grupo, o método quantitativo é o mais apropriado (BOTELHO; CRUZ, 2013). 
A pesquisa se caracteriza como descritiva, considerando-se que as pesquisas descritivas têm como objetivo principal estudar as características de um conjunto de indivíduos, além de ser útil no levantamento de opiniões, atitudes e crenças de uma população específica ou segmento dela (BOTELHO; CRUZ, 2013). Nesse sentido, Gil (2010) corrobora o conceito de que algumas pesquisas descritivas têm por objetivo estudar as características delimitadas de um grupo (como procedência, faixa etária, escolaridade, etc.), enquanto outras objetivam descobrir a existência de associações entre essas variáveis. Lakatos e Marconi (2017) frisam ainda que as pesquisas descritivas consistem em investigações de pesquisa empírica, onde o principal objetivo é o delineamento em características de fatos ou fenômenos, isolamento de variáveis principais ou chave, bem como a avaliação dessas variáveis.

Referente a amostra, optou-se por realizar a pesquisa no Instituto Federal Campus Caxias do Sul, devido as características da população a ser estudada, e também pela diversidade de idades e graus de instrução dos alunos, visto que o Instituto oferece cursos que vão desde o nível médio até o mestrado. A Tabela 1 quantifica o número de alunos matriculados de acordo com os respectivos cursos.

Tabela 1 - Quantitativo de alunos IFRS - Campus Caxias do Sul

\begin{tabular}{|c|c|}
\hline Ensino Médio & Total \\
\hline Técnico em Fabricação Mecânica & $174(\mathrm{SIGAA})+45(\mathrm{SIA})=219$ \\
\hline Técnico em Plástico & $178($ SIGAA $)+44(\mathrm{SIA})=222$ \\
\hline Técnico em Química & $176($ SIGAA $)+54(\mathrm{SIA})=230$ \\
\hline Técnico em Administração (Proeja) & 90 \\
\hline \multicolumn{2}{|l|}{ Curso Técnico Subsequente } \\
\hline Técnico em Plástico Subsequente & $33(\mathrm{SIGAA})+54(\mathrm{SIA})=87$ \\
\hline \multicolumn{2}{|l|}{ Curso Superior } \\
\hline Licenciatura em Matemática & $124+22^{*}(\mathrm{SIGAA})+7+3^{*}(\mathrm{SIA})=156$ \\
\hline Tecnologia em Processos Metalúrgicds & $177+9^{*}($ SIGAA $)+7+12^{*}($ SIA $)=205$ \\
\hline Engenharia Metalúrgica & $101+6^{*}=107$ \\
\hline Engenharia de Produção & $100+3^{*}=103$ \\
\hline Tecnologia em Processos Gerenciais & $92+7^{*}=99$ \\
\hline \multicolumn{2}{|l|}{ Pós-Graduação } \\
\hline $\begin{array}{c}\text { Mestrado Profissional em Tecnologia e } \\
\text { Engenharia de Materiais }\end{array}$ & $51+3^{\star}+8^{\star \star}=62$ \\
\hline TOTALDE ALUNOS & 1580 \\
\hline
\end{tabular}

Fonte: Registros acadêmicos IFRS - Campus Caxias do Sul (2019).

A técnica de amostragem utilizada neste estudo consiste em uma amostragem por conveniência. De acordo com Malhotra (2011) a amostragem por conveniência se define com uma amostra de elementos colhidos por conveniência do pesquisador. Nesse tipo de amostra os entrevistados ou respondentes geralmente são selecionados por estarem casualmente em um lugar ou momento convenientes à aplicação da pesquisa. Dentre os exemplos de amostragem por conveniência citados pelo autor estão o uso de alunos, grupos de igreja, 
membros de organizações sociais, abordagens aleatórias em shopping e lojas de departamento. Considerando que de acordo com a Tabela 1, o Campus possui 1580 alunos matriculados no semestre 2019/1, o percentual de retorno do questionário foi de 14,3\%, pois o tamanho da amostra desta pesquisa corresponde a duzentos e vinte e seis alunos do IFRS Campus Caxias do Sul.

Para executar a etapa de coleta de dados, utilizou-se a estratégia de questionários eletrônicos estruturados (Survey). O questionário foi elaborado visando atingir os objetivos propostos pela pesquisa, e foi adaptado de uma pesquisa validada no estudo de Scussel (2015). O questionário foi desenvolvido na ferramenta Google Forms, a qual permite coletar informações do público-alvo e compilar essas informações diretamente em uma planilha eletrônica para posteriores análises. De acordo com Mattar (2012), as principais vantagens em utilizar software de pesquisa estão na remessa automática para relação de e-mails, no fato das respostas serem digitadas diretamente pelo correspondente, no controle automático do retorno e no processamento contínuo das respostas recebidas.

Após desenvolver o questionário, executou-se a etapa de pré-teste. Essa etapa, tem o objetivo de evidenciar possíveis falhas existentes, como a inconsistência ou complexidade das questões, ambiguidades ou linguagem inacessível (LAKATOS; MARCONI, 2017). A fase de préteste foi realizada de quinze a dezoito de abril de 2019, e obteve nove respostas. O público escolhido para aplicação foi um público com características semelhantes ao alvo do estudo. A partir do pré-teste, procedeu-se à adequação do formulário, e chegou-se a um modelo final de questionário. O questionário foi enviado então a todos os alunos da instituição de ensino no dia 22 de abril de 2019. No dia 28 de abril de 2019 foi encaminhado novo e-mail para os diretórios acadêmicos dos cursos superiores e para o grêmio estudantil, solicitando auxílio na divulgação da pesquisa com o intuito de aumentar o número de respostas. O link do questionário permaneceu ativo por quatorze dias, sendo encerrado em 06 de maio de 2019. 0 instrumento de coleta, utilizou a interface lógica ilustrada na Figura 1. 
Figura 1 - Interface lógica do instrumento de coleta

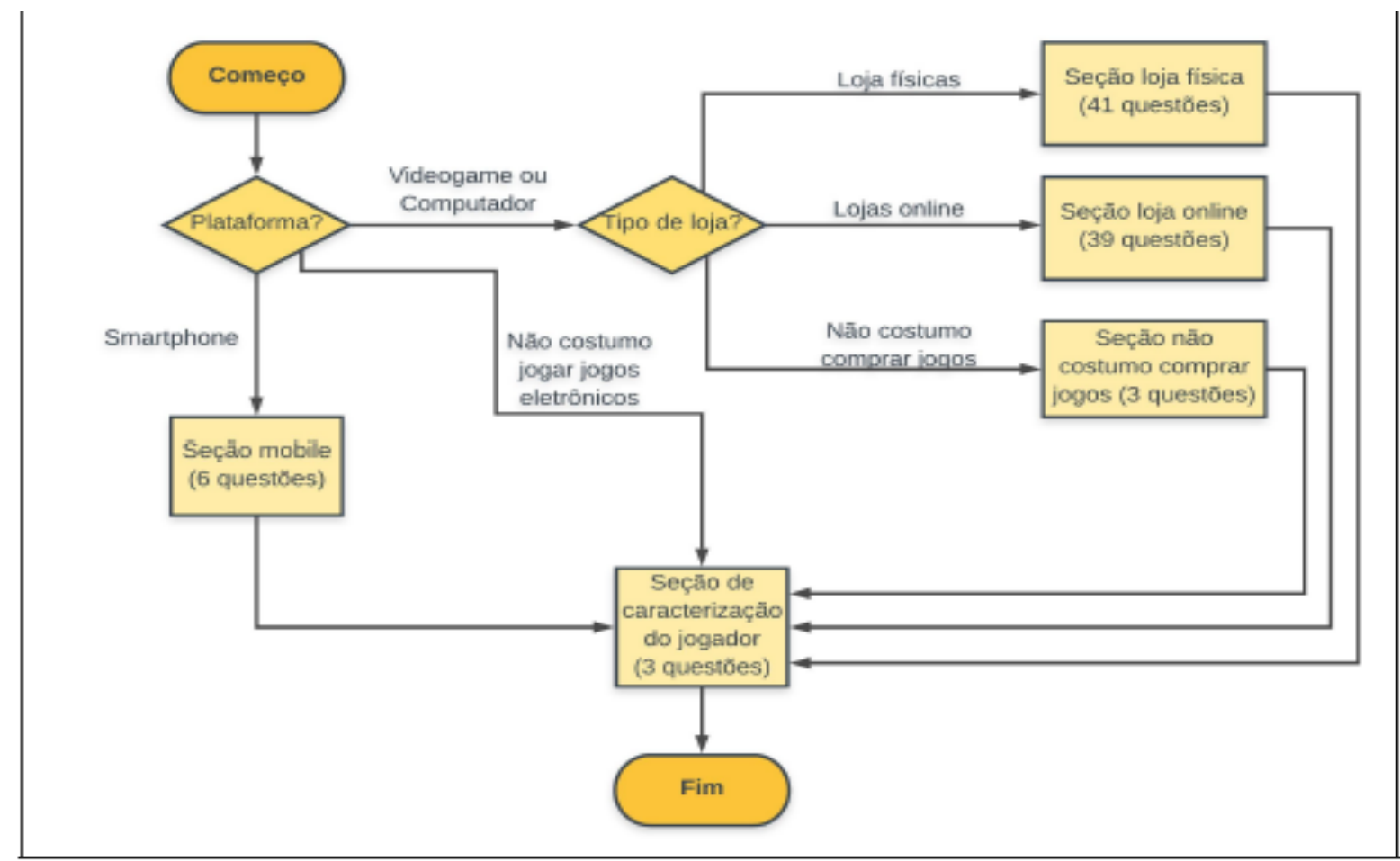

Fonte: Elaborado pelos autores (2019).

O questionário iniciava com a indagação acerca de qual plataforma o aluno mais utilizava para jogar, e de acordo com a resposta, o respondente era direcionado para outras sessões. Se o respondente escolhesse a opção "mobile", ele era direcionado para o bloco de perguntas "seção mobile" que continha 6 questões, e em seguida era direcionado para a "seção de caracterização do jogador", que possuía 3 questões, e o formulário era enviado.

Quando o estudante indicasse a opção "não costumo jogar jogos eletrônicos", ele era direcionado instantaneamente para a "seção de caracterização do jogador", e o formulário era submetido ao envio. Caso o respondente marcasse a opção "videogame" ou "computador", ele era questionado sobre o tipo de loja que geralmente usava para comprar jogos, e de acordo com a resposta era direcionado para o bloco de questões correspondente.

Os blocos de perguntas "seção loja física", "seção loja online" e seção "não costumo comprar jogos", possuíam 41, 39, e 3 questões respectivamente. Ao terminar de responder a seção, o aluno também era direcionado para a "seção de caracterização do jogador", e o formulário era enviado. Os blocos "seção loja física" e "seção loja online", concentravam os principais questionamentos referentes às práticas de relacionamento utilizadas pelas lojas. $\mathrm{Na}$ "seção mobile" esse tipo de questionamento não foi inserido, uma vez que pessoas que optam por jogar em smartphone têm opções limitadas de compra de jogos (loja de aplicativos do sistema operacional do aparelho).

As seções "seção loja física" e "seção loja online", possuíam 34 e 32 questões de concordância respectivamente. As questões eram 100\% afirmativas, e para medir o quanto 
cada respondente concordava com as afirmações que constavam nessas seções, foi utilizada uma escala de concordância Likert de cinco pontos, onde 1 significava "discordo totalmente", 2 significava "discordo em parte", 3 significava "não concordo nem discordo", 4 significava "concordo em parte" e 5 significava "concordo totalmente". A escala Likert é um método de pontuação somatória muito popular na medição de atitudes, pois é simples de ser aplicada e interpretada (ZIKMUND, 2006). Esse tipo de escala visa medir a intensidade das concordâncias e das discordâncias dos respondentes sobre as afirmações do questionário (MATTAR, 2012).

Ressalta-se que o questionário direcionou sua análise à percepção dos jogadores que jogam em computador ou videogame, e que compram jogos em lojas físicas ou lojas online, visto que concentrou seus questionamentos de práticas relacionais nas seções "seção loja física" e "seção loja online". Após a coleta dos dados, ocorreu a tabulação dos mesmos em planilhas eletrônicas com o objetivo de serem medidos e analisados por meio de métodos estatísticos descritivos.

\section{RESULTADOS E DISCUSSÃO}

Nesta seção são descritos os resultados da pesquisa, iniciando-se pela caracterização da amostra, seguido pelos subcapítulos "plataforma", "preferência de loja", e "análise dos resultados". A Figura 2 exibe o quantitativo de respondentes em cada seção.

Figura 2 - Quantitativo de respondentes por seção

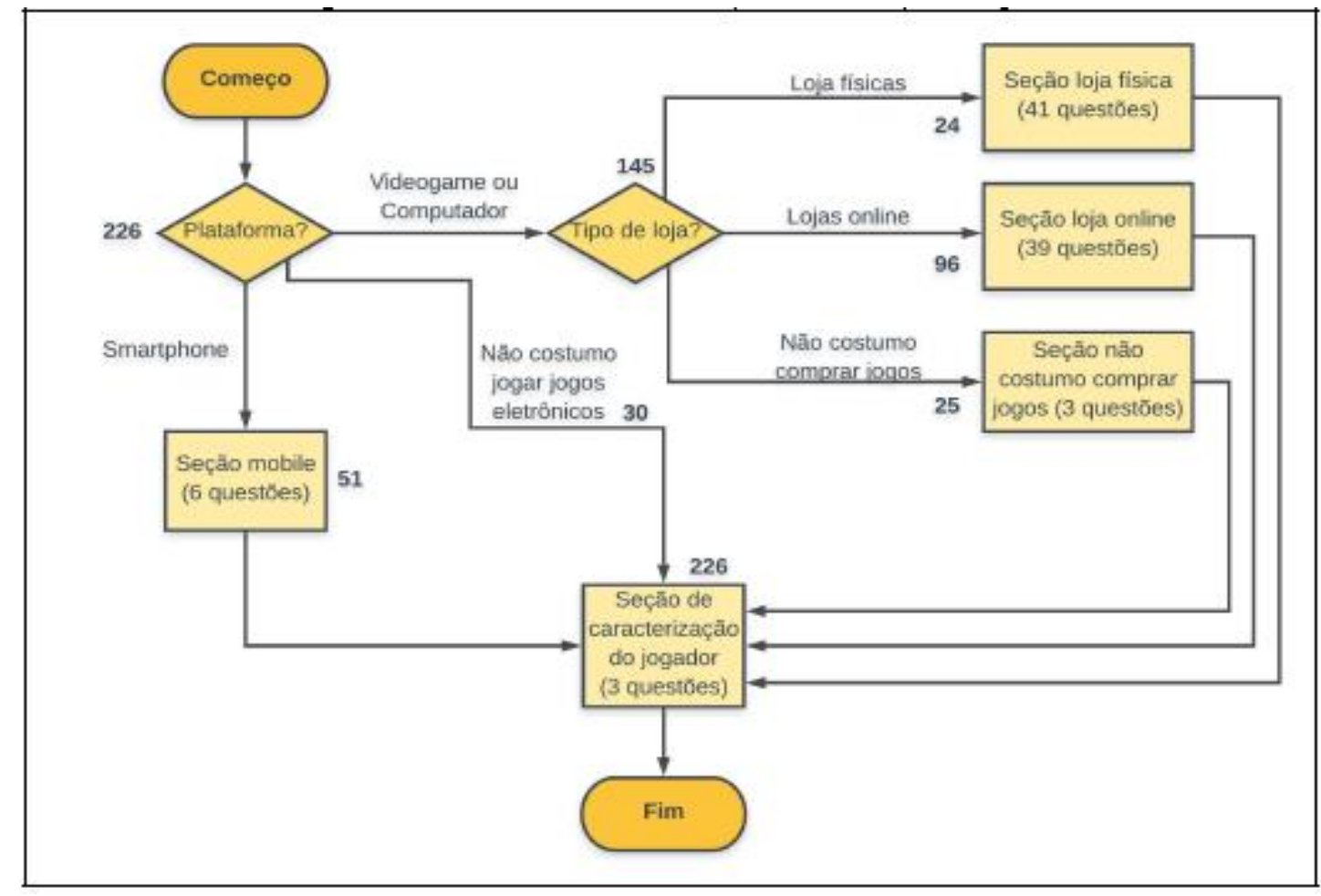

Fonte: Elaborado pelos autores (2019). 


\section{CARACTERÍSTICAS GERAIS DA AMOSTRA}

Quanto a faixa etária da amostra, predominaram alunos até 16 anos (34,5\%), e de 17 a 20 anos (33,6\%), conforme apresentado na Figura 3.

Figura 3 - Faixa etária da amostra

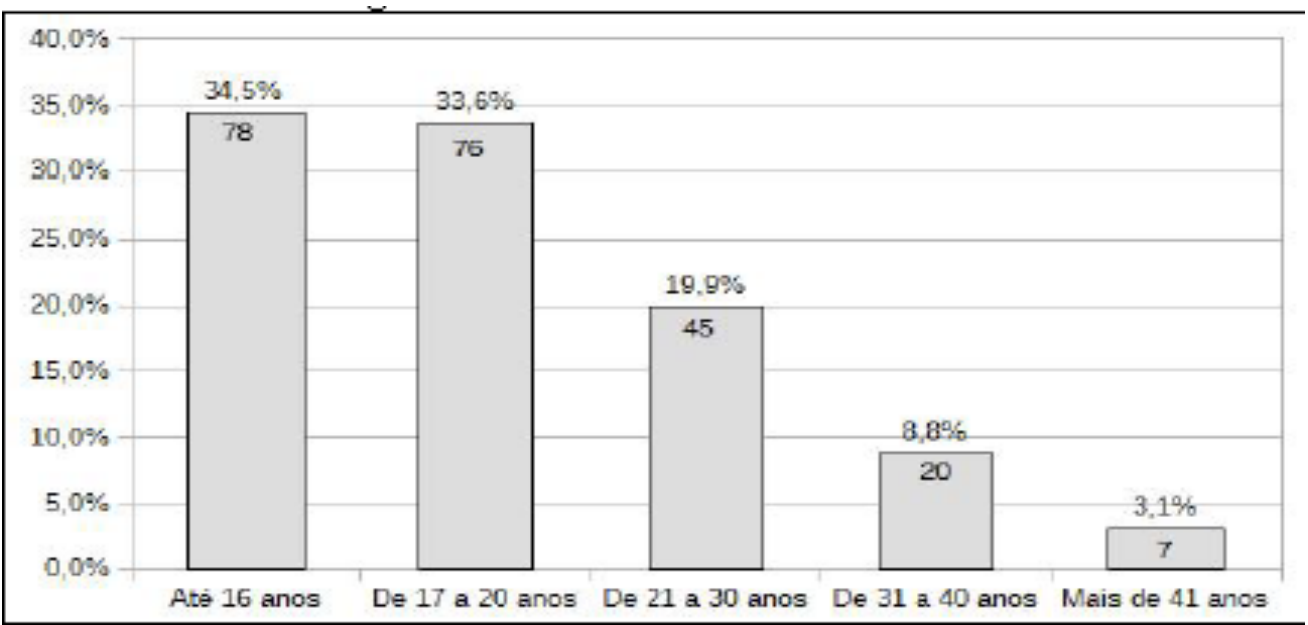

Fonte: Elaborada pelos autores (2019). Base: 226 respondentes.

Quanto ao sexo dos respondentes, a amostra está caracterizada predominantemente por alunos do sexo masculino, onde cento e setenta e quatro alunos (77\%) declararam ser do sexo masculino, enquanto cinquenta e dois (23\%) declararam ser do sexo feminino. Dentre os respondentes, cento e quinze (50,9\%) afirmaram possuir o ensino médio completo, e oitenta $(35,4 \%)$ declararam possuir o ensino fundamental completo.

\section{PLATAFORMA}

Referente a plataforma, noventa e nove $(43,8 \%)$ tem a preferência por jogar em computador. A plataforma "smartphone" foi escolhida por cinquenta e um alunos $(22,6 \%)$ e aparece na segunda posição, enquanto a plataforma "videogame" aparece na terceira colocação, sendo a preferida por quarenta e seis alunos. Destaca-se ainda que trinta alunos $(13,3 \%)$ declararam não jogar jogos eletrônicos.

Analisando os dados coletados na seção plataforma não se observou semelhança aos resultados apontados na Pesquisa Game Brasil (2018) quanto a plataforma preferida pelos jogadores, visto que para os respondentes daquela pesquisa, a plataforma mobile foi apontada como favorita por $43,6 \%$, e o computador apareceu apenas na terceira colocação com $14,5 \%$ da preferência.

\section{PREFERÊNCIA DE LOJA}

Após escolher o tipo de plataforma favorita para jogar, caso o aluno escolhesse a 
opção "videogame" ou "computador", ele era direcionado para a "seção preferência de loja", onde foi questionado quanto a sua preferência de modelo de loja quando da compra de jogos eletrônicos. Observou-se que 66,2\% dos respondentes compram preferencialmente em lojas online incluindo as lojas do próprio console, 17,2\% afirmaram não comprar jogos, e 16,6\% informaram comprar em lojas físicas preferencialmente.

\section{LOJAS FÍSICAS}

Com relação aos gêneros de jogo, observou-se que os gêneros favoritos de jogos são "tiro/shoter" (20,8\%), seguido pelo gênero "ação/aventura" (16,7\%), e que os gêneros "RPG", "esportes" e "estratégia" empataram em 11,1\% da preferência. Considerando os estudantes que preferem comprar em lojas físicas, quanto ao fabricante do console, verificou-se que 58,3\% informaram que jogam em aparelhos da fabricante Sony, enquanto 33,3\% em aparelhos da fabricante Microsoft e 8,3\% indicaram jogar somente em computador. Com relação à loja física na cidade de Caxias do Sul, identificou-se predominância das lojas "O.R games" e "Topy games" que representam 58,3\% da amostra. A opção "Livraria Saraiva" figura na terceira colocação com 20,8\%, enquanto "Multisom", "Game Store Collection" e outras lojas juntas também somam o percentual de $20,8 \%$.

Quando questionados sobre o tempo em que são clientes da loja, predominou o período compreendido entre 1 e 5 anos (58,3\%), já no período que se compreende entre 5 e 10 anos, 29,2\%, e 12,5\% consideram-se clientes há menos de 1 ano. Este resultado possivelmente esteja relacionado com a idade predominante dos respondentes, visto que 68,1\% são jovens com no máximo 20 anos de idade. Com relação ao fator que levou o aluno aquela loja pela primeira vez, observou-se que o fator predominante foi a "indicação de amigos" (45,8\%) e a "localização" (29,2\%). "Divulgação em redes sociais" obteve 8,3\% de escolha, "anúncio em jornal/revista/tv" obteve 4,2\%, e outros motivos somaram $12,5 \%$.

McKenna (1991, apud BRETZKE, 2006), considera a comunicação boca-a-boca como um dos principais benefícios do marketing de relacionamento, sendo que este fenômeno promove a marca e gera vendas adicionais por indicação, e geralmente é observado em clientes considerados "advogados da marca", onde percebe-se grande nível de lealdade. Nesse sentido, os dados obtidos corroboram o que afirmou o autor, uma vez que 45,8\% afirmaram ter comprado naquela loja a primeira vez devido a indicação de algum amigo. No entanto, 45,8\% dos respondentes informaram que nunca ficam sabendo das promoções ou novidades da loja, $25 \%$ apontaram as redes sociais como principal meio, $12,5 \%$ indicaram que sabem das ofertas através de amigos ou pelo site, e 4,2\% por e-mail.

Bretzke (2006, p. 422), afirma que "a oferta é a peça central da mensagem de marketing direto para a obtenção de uma resposta satisfatória e imediata", e considera que o 
marketing direto é uma ferramenta fundamental do marketing relacional. Analisando as lojas físicas de Caxias do Sul pela ótica dessa autora, entende-se que elas estão aquém do esperado no que se refere a divulgação de suas ofertas, sendo esse um ponto indicado para ação de melhoria. Apesar disso, entre os respondentes 62,5\% informaram ter comprado da loja indicada várias vezes, o que poderia indicar uma tendência à retenção, aspecto a ser aproveitado pela loja.

Após a tabulação das 816 respostas das questões de concordância, observou-se que, de forma geral, o ponto número 4 da escala Likert (concordo em parte) foi o mais selecionado $(31,62 \%)$, seguido pelos pontos 3 (não concordo nem discordo) (31,25\%), 5 (concordo totalmente) (14,58\%), 1 (discordo totalmente) (13,85\%) e 2 (discordo em parte) (8,70\%).

Agrupando as notas de concordância (4 e 5), isolando o ponto neutro da escala (3), e agrupando as notas de discordância (1 e 2), observa-se que, de forma global, 46,2\% concordam parcial ou totalmente com as afirmações, 31,25\% não concorda nem discorda, e 22,55\% discorda parcial ou totalmente. Nesse sentido, pode-se afirmar que o nível de concordância é aproximadamente 104\% maior em relação ao nível de discordância entre os alunos que costumam efetuar suas compras nas lojas físicas de Caxias do Sul.

Agrupando os resultados de acordo com a moda de cada questão, chegou-se a Tabela 2, que apresenta as perguntas classificadas de acordo com suas respectivas modas. Ao dispor os resultados obtidos desta forma, foi possível mensurar individualmente o nível de concordância dos estudantes acerca das práticas relacionais das lojas físicas analisadas. A análise das percepções foi realizada ao final deste capítulo.

Tabela 2 - Agrupamento das notas de acordo com a moda - loja física

\begin{tabular}{c|c|c}
\hline Nota & Unimodais & Perguntas \\
\hline 5 & 3 & 6,13 e 20. \\
\hline 4 & 11 & $1,2,7,10,11,18,19,22,29,32$ e 34 \\
\hline 3 & 9 & $3,4,5,8,9,15,24,25$ e 27 \\
\hline 2 & 0 & Nenhuma \\
\hline 1 & 5 & $14,26,28,31$ e 33. \\
\hline & & 12 \\
\hline Empate & Bimodais & $16,21,23$ e 30. \\
\hline 5 e 4. & 1 & 17 \\
\hline 4 e 3. & 4 & \\
\hline 3 e 2. & 1 &
\end{tabular}

Fonte: Elaborado pelos autores (2019).

\section{LOJAS ONLINE}

Após escolher a opção "lojas online" na seção de preferência de loja, o respondente era direcionado ao bloco de perguntas "seção loja online", composto por sete questões de múltipla escolha e por trinta e duas questões de concordância. Com relação aos gêneros de jogo, observou-se que os gêneros favoritos de jogos são "tiro/shoter" (25\%), seguido pelo 
gênero "ação/aventura" (18,8\%). Os gêneros "RPG" e "estratégia" alcançaram 17,7\% e 12,8\%. Considerando os estudantes que preferem comprar em lojas online, quanto ao fabricante do console, observou-se que 51\% informaram que jogam somente em computador, enquanto $24 \%$ afirmaram jogar em aparelhos da fabricante Sony, 19,8\% indicaram jogar em aparelhos da fabricante Microsoft, e 5,2\% afirmaram jogar em aparelhos da fabricante Nintendo. Com relação a qual loja online, percebeu-se grande prevalência da loja/software "Steam", com $71,9 \%$ da preferência. A loja do próprio console aparece na sequência, com 14,6\%. As grandes redes varejistas aparecem na terceira posição, com 6,3\%. O site "mercado livre" obteve $1 \%$ das respostas, enquanto outras lojas somaram um total de 6,3\% conforme mostra a Figura 4.

Figura 4 - Loja online favorita

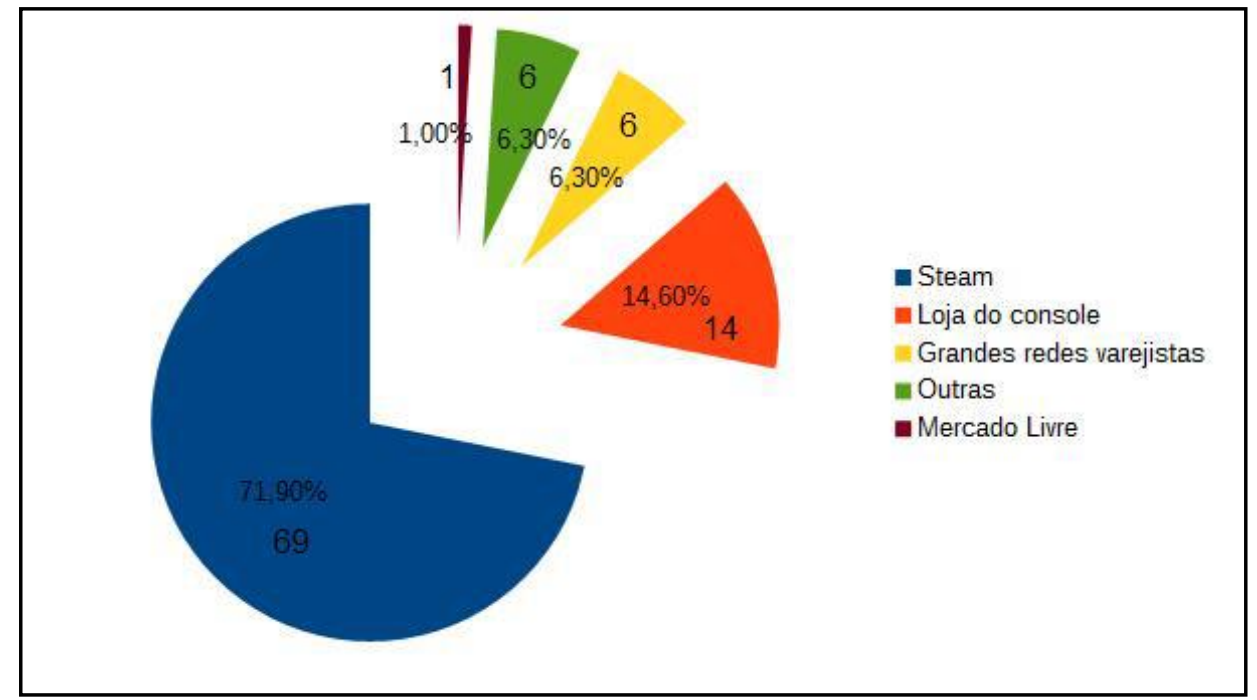

Fonte: Elaborado pelos autores (2019). Base: 96 respondentes.

A loja Steam foi lançada em 2003 com o intuito de vender jogos digitais, tendo evoluído nos últimos anos para uma plataforma completa, com chat entre amigos, coleções, lista de desejos, eventos e promoções temáticas, entre outros incrementos. Essa evolução fez com que a loja se tornasse líder de mercado em seu segmento e também referência para os concorrentes que surgem. Esta loja permite que o gamer crie um perfil na plataforma e possa vender itens digitais obtidos em jogos, contudo, a loja é direcionada a jogadores que jogam em computador, e não vende jogos de console (VINHA, 2019).

A liderança de mercado desta loja pôde ser corroborada nesta pesquisa através da sua ampla prevalência entre os alunos que informaram efetuar compras de jogos em lojas online, sugerindo que a empresa é assertiva em seus direcionamentos estratégicos e está em sintonia com seu público-alvo. Quando questionados sobre o tempo em que são clientes da loja, observou-se que a maioria se considera cliente do período compreendido entre 1 e 5 anos (55,2\%), já no período que se compreende entre 5 e 10 anos, 28,1\%, enquanto 9,4\% consideram-se clientes há menos de 1 ano, e 7,3\% há mais de 10 anos. Na questão número cinco, os respondentes deviam informar o principal motivo que os levou a comprar naquela 
loja específica a primeira vez. A opção "ofertas" obteve 38,5\% das respostas, seguida pela opção "indicação de amigos" com 32,3\%, já "comodidade" somou 14,6\% das respostas. "Divulgação em redes sociais", "indução através de página de busca" e "outros", obtiveram 4,2\%, 3,1\% e 7,3\% respectivamente.

Novamente o fator "indicação de amigos" apresentou percentual elevado, figurando na segunda posição. Contudo, diferentemente das lojas físicas, as lojas online demonstraram maior empenho na divulgação de sua marca, pois o fator "ofertas" foi o fator mais lembrado quando os alunos foram questionados sobre o fator que os levou a comprar naquela loja a primeira vez. Este empenho das lojas online fica evidente visto que quando os alunos foram questionados acerca de como ficavam sabendo das novidades/promoções da loja, as respostas foram maioritariamente "site" seguido por "e-mail" e "redes sociais", com 32,3\%, 27,1\% e $22,9 \%$ respectivamente, enquanto a opção "nunca fico sabendo das promoções/ofertas" somou apenas 3,1\%. Observou-se que dentre os respondentes, $89,6 \%$ informaram ter comprado da loja indicada várias vezes, o que poderia indicar uma tendência à retenção, aspecto a ser aproveitado pela loja analisada pelo estudante.

Após a tabulação das 3072 respostas das questões de concordância, observou-se que, de forma geral, o ponto número 5 da escala Likert (concordo totalmente) foi o mais selecionado $(38,12 \%)$, seguido pelos pontos 4 (concordo parcialmente) $(25,62 \%), 3$ (nem concordo nem discordo) (20,83\%), 1 (discordo totalmente) (7,81\%) e 2 (discordo em parte) (7,62\%). Agrupando as notas de concordância (4 e 5), isolando o ponto neutro da escala (3), e agrupando as notas de discordância ( 1 e 2), observa-se que, de forma global, 63,74\% concordam total ou parcialmente com as afirmações, 20,83\% não concorda nem discorda, e apenas 15,43\% discorda total ou parcialmente. Nesse sentido, pode-se afirmar que o nível de concordância é aproximadamente 313\% maior em relação ao nível de discordância entre os alunos que costumam efetuar suas compras em lojas online.

\section{NÃO COSTUMO COMPRAR JOGOS}

Caso o respondente escolhesse a opção "não costumo comprar jogos" na seção de preferência de loja, ele era direcionado ao bloco de perguntas "seção não costumo comprar jogos", contendo 3 questões que objetivavam principalmente descobrir o motivo pelo qual o jogador não compra jogos eletrônicos. Quanto aos gêneros de jogo, as opções "ação/aventura", "RPG" e "tiro/shoter" foram as que tiveram maior índice de escolha, conforme ilustra a Figura 5. 
Figura 5 - Gêneros de jogo favoritos - não costumo comprar jogos

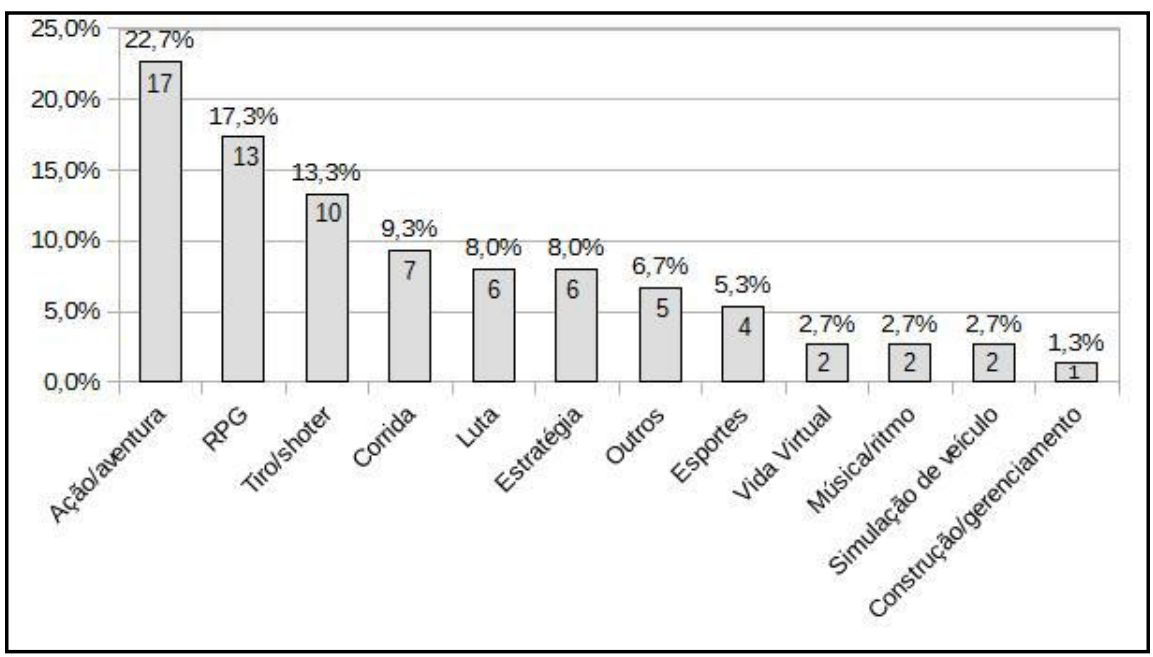

Fonte: Elaborado pelos autores (2019). Base: 25 respondentes.

Quanto a fabricante do console que possuem na residência, $40 \%$ afirmaram jogar somente em computador, 28\% escolheram "Sony", 16\% escolheram "Microsoft" e outros 16\% afirmaram não possuir videogame na residência. A questão três questionava os três principais motivos pelo qual o aluno não comprava jogos. A alternativa mais escolhida foi a "preços muito elevados" (40,4\%). O resultado obtido nesta questão, corrobora a afirmação dos pesquisadores da Pesquisa Game Brasil (2018), onde os mesmos afirmam que o consumo de jogos digitais é um entretenimento considerado caro pela maior parte da população, tanto em termos de software quanto em termos de hardware.

\section{SEÇÃO MOBILE}

Quando questionado sobre a plataforma que mais utilizava para jogar, caso o respondente escolhesse "mobile/smartphone", ele era direcionado para a "seção mobile", onde continha 6 questões de múltipla escolha, e objetivava descobrir principalmente o fator que fazia com que o aluno preferisse jogar em smartphone em vez de outras plataformas.

$\mathrm{Na}$ primeira questão, quanto aos gêneros de jogo, as opções "estratégia", "ação/aventura" e "construção/gerenciamento" foram as mais escolhidas, com 19\%, 15,7\% e $11,8 \%$ respectivamente. Quando os respondentes foram questionados se costumavam jogar jogos que não são gratuitos ou jogos que exigem pagamentos para continuar jogando, a maioria optou pela opção "Não, jogo somente jogos 100\% grátis ou jogos que permitem continuar jogando sem pagar" (56,9\%).

Comparando esta informação com os dados da faixa média de renda familiar per capita do IFRS Campus Caxias do Sul, pode-se sugerir que os alunos optam por jogar jogos gratuitos também pelo fato de não disporem de recursos financeiros suficientes para serem aplicados em jogos eletrônicos, visto que uma parcela significativa dos alunos possui renda 
familiar per capita entre um salário-mínimo e um salário-mínimo e meio. A Figura 6 exibe os dados econômicos dos alunos do Campus.

Figura 6 - Renda familiar per capita - IFRS Campus Caxias do Sul

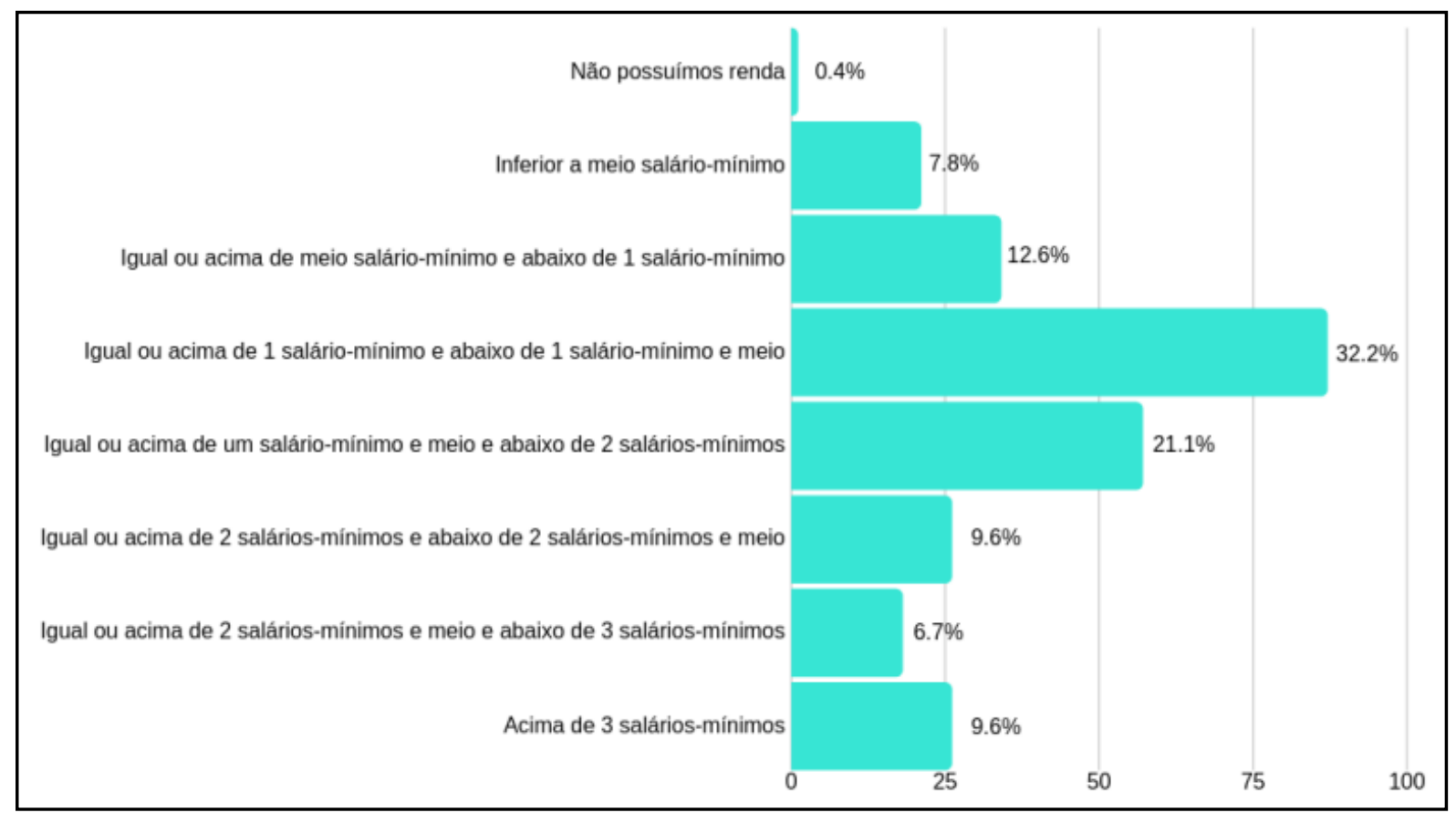

Fonte: Site IFRS (2019).

A praticidade foi o fator com maior representatividade $(62,7 \%)$ quando os alunos foram questionados a respeito do fator que faz com que eles prefiram jogar em smartphone em vez de outras plataformas, o segundo fator com maior representatividade $(27,5 \%)$ foi a mobilidade. Dentre os cinquenta e um respondentes desta seção, 38 afirmaram jogar também em computador ou videogame enquanto 13 afirmaram jogar apenas em smartphone, correspondendo a 74,5\% e 25,5\% respectivamente. Questionados sobre o fabricante do console que possuem em sua residência, 41,2\% escolheram a opção "não possuo console/videogame", 25,5\% escolheram "Sony", 15,7\% "Microsoft", 11,8\% afirmaram jogar apenas em computador e 5,9\% escolheram "Nintendo".

A última pergunta desta sessão questionava o aluno sobre o tipo de loja que ele geralmente comprava jogos no caso dele possuir videogame. Dos respondentes que possuem videogame, 27,5\% escolheram a opção "loja física", 17,6\% escolheram a opção "loja online" e 5,9\% optaram pela opção "não costumo comprar jogos".

\section{ANÁLISE DAS QUESTÕES DE MÚLTIPLA ESCOLHA}

A amostra está caracterizada pela predominância de indivíduos do sexo masculino na faixa de 16 a 20 anos, e que declararam possuir o ensino médio completo. Observou-se que a plataforma favorita dos respondentes é o computador, e a preferência quanto ao tipo de loja 
na hora de efetuar compras de jogos eletrônicos são as lojas online.

Dentre os que preferem efetuar compras em lojas físicas, os três gêneros de jogos favoritos foram: "tiro" e "ação", sendo que os gêneros "RPG" /"esportes"/"estratégia" ficaram empatados na terceira colocação. Quanto ao aparelho em que jogam a marca mais citada foi "Sony". A loja de Caxias do Sul mais mencionada foi "O.R games". A maioria dos respondentes afirmaram já terem feito mais de uma compra na loja que costumam comprar, são clientes entre 1 e 5 anos, e ficaram sabendo da loja por indicação de amigos, contudo declararam que nunca ficam sabendo das promoções ou ofertas da loja que geralmente compram.

Observou-se também que entre os que preferem efetuar compras em lojas online, os três gêneros de jogos favoritos foram "tiro", "ação" e "RPG" e quanto ao aparelho em que jogam a maioria afirmou que joga em computador. A loja online mais lembrada foi "Steam". Da mesma forma, a maioria dos respondentes afirmaram já terem feito mais de uma compra na loja que costumam comprar e são clientes entre 1 e 5 anos. Os estudantes sinalizaram que ficaram sabendo da loja por meio de alguma oferta que a loja fez, e declararam que ficam sabendo das promoções ou ofertas da loja através do site corporativo. Dentre os alunos que afirmaram que não compram jogos, também se observou que os gêneros "ação", "RPG" e "tiro" são os favoritos. O computador foi eleito como plataforma favorita por esse perfil de aluno. A maioria informou que não compra jogos porque consideram os preços muito elevados, ou preferem jogos que são 100\% gratuitos ou ainda não possuem condições financeiras para adquirirem jogos eletrônicos.

Já entre os respondentes que jogam preferencialmente em smartphone, os três gêneros de jogo eleitos foram "estratégia", "ação" e "construção/gerenciamento". A maioria informou que somente jogam jogos $100 \%$ gratuitos, que jogam em smartphone por praticidade, mas que também jogam em outras plataformas, contudo não possuem console e os que possuem console preferem comprar em lojas físicas.

Na Pesquisa Game Brasil (2018) a Microsoft, através do seu console "Xbox 360", foi aquela que se mostrou mais presente na casa dos respondentes, diferentemente deste estudo, onde em nenhuma das seções analisadas a fabricante Microsoft foi eleita como o fabricante do console que o aluno costuma jogar e o computador foi eleito como plataforma favorita pelos alunos. O fato de os adolescentes preferirem efetuar compras em lojas online vai ao encontro da afirmação de que o Brasil é líder de vendas online da América Latina e ocupa a 10a posição no ranking mundial no e-commerce (CASAL JUNIOR, 2019). Destaca-se também que o computador ou " $p c$ gamer" possui diferenciais competitivos sobre os consoles, como o multiplayer gratuito, o preço dos jogos e a variedade dos títulos (MELLO, 2018).

Sugere-se que as lojas físicas invistam em ferramentas de divulgação de seu portfólio de produtos, para que aumentem seu market share e ampliem seus resultados. Recomenda-se também que as lojas atentem às mudanças que estão acontecendo no mercado, 
principalmente no que diz respeito ao streaming de jogos, visto que esta tecnologia pode ser encarada como ameaça direta ao comércio varejista físico. Para as lojas online sugere-se que elas continuem investindo na diversificação de seu portfólio de produtos e serviços objetivando realizar ações que estejam em consonância com seus direcionadores estratégicos. Sugere-se que elas hajam com cautela com relação a investimentos massivos neste setor, visto que o mercado está passando por constante transformação.

\section{ANÁLISE DAS QUESTÕES RELACIONAIS}

As 34 questões de concordância presentes na "seção loja física", indicaram que, de modo geral as questões 6 (Q6), 13 (Q13), e 20 (Q20) foram aquelas que obtiveram maior índice de concordância entre os respondentes dessa seção. A Q6 versava sobre a loja tratar o cliente com respeito, enquanto a Q13 tratava de a loja cumprir o que prometia em suas vendas e a Q20 indagava sobre os ambientes físicos da loja serem agradáveis.

Por outro lado, as questões 14 (Q14), 26 (Q26), 28 (Q28), 31 (Q31) e 33 (Q33) foram aquelas que obtiveram menor índice de concordância entre os respondentes da "seção loja física". A Q14 indagava o respondente se a loja o convidava para eventos, a Q26 questionava se o respondente recebia brindes/presentes/cortesias da empresa avaliada, a Q28 abordava se a empresa em questão fornecia atendimento personalizado ao consumidor, a Q31 questionava se a loja se fazia presente em momentos importantes na vida do aluno, e a Q33 questionava sobre a loja possuir o serviço de entrega domiciliar.

Enquanto a "seção loja física" obteve apenas três questões que obtiveram índice de maior concordância, a "seção loja online" obteve dezenove questões de máxima concordância (Q1, Q2, Q6, Q8, Q10, Q12, Q13, Q16, Q17, Q18, Q20, Q21, Q23, Q24, Q25, Q27, Q28, Q30 e Q32), e apenas três questões com concordância mínima (Q14, Q29 e Q31). Na "seção loja online", as questões 14 (Q14), 29 (Q29) e 31 (Q31), questionavam respectivamente se a loja convidava o cliente para eventos, se a loja se fazia presente em momentos importantes na vida do aluno, e se a loja online disponibilizava um canal físico para o consumidor retirar o produto que foi comprado no site da loja.

Portanto, analisando individualmente as questões com menor índice de percepção, observou-se que duas questões apresentaram nível de percepção baixa nos dois tipos de loja, as quais foram as questões que indagavam o aluno se a loja o convidava para eventos, e as questões que interrogavam se a loja se fazia presente em momentos importantes da vida do aluno, como seu aniversário, por exemplo. Observou-se também que em ambas as categorias de loja, não existem diversidade de opções para o cliente receber o produto adquirido, senão as tradicionais formas de entrega.

Percentualmente os pontos 4 e 5 (concordo em parte/concordo totalmente) da escala 
Likert da "seção loja física" somaram 46,2\% das respostas, enquanto os mesmos pontos na "seção loja online" somaram 63,74\% das respostas. Esses percentuais demonstram que, de forma geral, as práticas de relacionamento das lojas online são mais percebidas pelos seus clientes em relação aos clientes das lojas físicas.

Já os pontos 2 e 1 (discordo em parte/discordo totalmente) da escala Likert da "seção loja física" somaram $22,55 \%$ das respostas, enquanto os mesmos pontos na "seção loja online" somaram apenas $15,43 \%$ das respostas. Esses percentuais demonstram que, de forma geral, as práticas de relacionamento das lojas físicas são menos percebidas pelos seus clientes em relação aos clientes das lojas online. Então, após a análise detalhada dos resultados das questões relacionais, pode-se afirmar que as lojas online estão mais atentas no que se refere ao relacionamento com seus clientes. Contudo, tanto as lojas físicas quanto as lojas online possuem melhorias a serem implementadas.

Para as lojas físicas sugere-se que adotem políticas de recompensa através de cortesias (brindes/descontos) aos seus clientes especiais, que realizem eventos para estreitar o relacionamento com seus clientes, que na medida do possível forneçam atendimento personalizado de acordo com cada consumidor, que se façam presentes de alguma forma em momentos importantes na vida de seus clientes, e que ponderem implantar um serviço de entrega domiciliar para ampliar a comodidade aos mesmos.

Para as lojas online a sugestão também é de que elas realizem eventos para que o relacionamento com seus consumidores seja estreitado, que elas se façam presentes de alguma forma em datas importantes para seus clientes, e que elas ponderem a construção de parcerias estratégicas com lojas físicas para que seus consumidores consigam retirar uma compra online em uma loja física, ampliando as formas de entrega do produto ao consumidor e gerando conveniência ao cliente.

\section{CONSIDERAÇÕES FINAIS}

O que se observa na revisão da literatura, é que o mercado de games vem batendo recordes de faturamento ano após ano. A internet possibilita um contato direto das lojas com seus clientes, e por possuir essa característica, elas conseguem se manter em um mercado altamente competitivo, frequentemente utilizando a estratégia de competição por preço. Com a popularização da internet, é notável a alavancagem das receitas do varejo online. Esse aumento nas vendas neste segmento se deve, em parte, ao fato destas lojas possuírem alta tecnologia empregada em sua operação.

Por outro lado, as lojas físicas normalmente possuem um orçamento reduzido para investimento, gerando certa desvantagem nesse panorama competitivo, o que constantemente as faz competir por diferenciação. São diversas as ferramentas de marketing 
relacionamento que podem auxiliar as organizações no atingimento de seus objetivos. Contudo, depende de cada empresa a iniciativa de introduzir essa filosofia em seus processos. Se as ferramentas de marketing relacional forem corretamente empregadas, o retorno esperado para organização deve acontecer na forma de retenção e fidelidade de clienteschave, um ativo relevante e desejado pelas organizações que visam maximizar seus resultados.

O segmento de games é um segmento que fatura bilhões de dólares ao ano, e as empresas inseridas neste mercado estão buscando constantemente estratégias de diferenciação perante os consumidores. As ferramentas de marketing de relacionamento permitem uma aproximação e um entendimento maior dos desejos e necessidades destes consumidores. Essa aproximação visa principalmente a repetição do processo de compra com a consequente fidelização e retenção de clientes chave. Contudo, mais do que fidelizar, o marketing relacional está diretamente vinculado à construção de relacionamentos que visam benesses com todas as organizações ou pessoas que de alguma forma interajam com a empresa. Entretanto, implantar as ferramentas do marketing de relacionamento pode ser algo bastante desafiador, pois inúmeras vezes, para se lograr êxito na implantação dessas ferramentas, se faz necessária uma mudança de cultura em todo o âmbito organizacional.

Pode-se afirmar que o objetivo principal da pesquisa foi atingido, pois através das questões de concordância foi possível verificar a percepção dos gamers do IFRS Campus Caxias do Sul acerca das práticas relacionais utilizadas pelas lojas do varejo físico e online. A pesquisa possibilitou também o atingimento de objetivos específicos, como a identificação do tipo de loja que mais utiliza as ferramentas de marketing de relacionamento, onde observou-se a prevalência da percepção das estratégias de marketing relacional utilizadas pelas lojas do varejo online sobre as estratégias das lojas físicas.

Por meio da análise das questões de concordância também foi possível a verificação das práticas com maiores e menores níveis de percepção dos consumidores e por meio da análise das questões de múltipla escolha foi possível identificar gostos e preferências dos alunos no que diz respeito ao universo dos jogos eletrônicos. Por meio da imersão no tema de marketing, esta pesquisa permitiu ao autor deste estudo um maior entendimento acerca do universo de games, ao mesmo tempo em que possibilitou uma amplitude de conhecimento a respeito do tema do marketing de relacionamento, sendo possível tecer sugestões as empresas inseridas no segmento de vendas de jogos eletrônicos, e também apontar melhorias em estratégias relacionais com baixo nível de percepção.

A pesquisa levantou diversos dados acerca da percepção e das preferências dos alunos do IFRS - Campus Caxias do Sul sobre o universo de games. Para sua confecção foi necessário o emprego de muita dedicação, leitura e imersão ao tema do marketing de relacionamento. Foi um trabalho bastante intenso e realizado pelo acadêmico ao longo dos últimos três semestres do curso de Tecnologia em Processos Gerenciais. Ao longo de cada semestre, o 
trabalho foi sendo lapidado e melhorado, visando atingir os objetivos nele propostos. O fato de nunca antes ter realizado uma pesquisa de cunho científico foi algo bastante desafiador ao acadêmico, pois foram inúmeras as dificuldades enfrentadas para a confecção deste trabalho. Contudo, através da dedicação da professora orientadora, e através do empenho do acadêmico ao trabalho, foi possível a sua conclusão, onde foram atingidos os objetivos gerais e específicos, e todas as dificuldades se mostraram ínfimas diante dos novos aprendizados que este trabalho proporcionou.

Considerando que a taxa de retorno da população-alvo foi de aproximadamente $14,3 \%$, e por se tratar de uma amostra não probabilística, as informações que constam neste trabalho expõem a opinião de uma amostra e os resultados não devem ser generalizados. Outra limitação desta pesquisa está no fato de usar um método exclusivamente quantitativo. Através desse método pôde-se mensurar os dados da amostra, contudo, se um método qualitativo fosse usado concomitantemente seria possível uma maior amplitude de análise acerca das percepções dos alunos. Conforme as limitações citadas, a ampliação da amostra em estudos futuros seria desejável para corroborar os resultados encontrados e também para obter um panorama mais fidedigno acerca das preferências e percepções dos alunos da instituição. Em próximos estudos também é indicada a associação de um método qualitativo à pesquisa, visando a ampliação do subsídio de informações coletadas a respeito dos alunos.

Sugere-se que em pesquisas futuras o pesquisador opte se possível por uma técnica de amostragem probabilística, propiciando uma análise mais robusta dos dados colhidos. Outra sugestão é direcionar o foco do instrumento de coleta de dados somente as questões relativas ao marketing de relacionamento e aplicá-lo posteriormente em um público específico de gamers, direcionando assim a análise da pesquisa integralmente as questões relacionais.

\section{REFERÊNCIAS}

AQUINO, Mariah. Popularização da banda larga contribuiu para o crescimento do streaming. 2019. Disponível em: https//www.correiobraziliense.com.br/app/noticia/diversao-earte/2019/05/15/interna_diversao_arte,754992/popularizacao-da-banda-larga-contribuiupara-ocrescimento-do-streamin.shtml. Acesso em: 26 maio 2019.

BORGES, Joe. De volta para o passado: ascensão e queda das videolocadoras. 2016. Disponível em: https://zasocorp.com/2016/06/01/de-volta-para-o-passadoascensaoe-queda-das-videolocadoras/. Acesso em: 26 maio 2019.

BOTELHO, Joacy Machado; CRUZ, Vilma Aparecida Gimenes da. Metodologia científica. São Paulo: Pearson Education do Brasil, 2013. 135 p.

BRASIL. Assessoria de Comunicação. Ministério da Cultura (Ed.). Mercado de jogos eletrônicos cresce em todas as regiões do País, aponta 2o Censo de games. 2018. Disponível em: 
http://www.cultura.gov.br/feed-geral/-/asset_publisher/G7Zpw3dqBUVE/content/mercadode-jogos-eletro>. Acesso em: 10 out. 2019.

BRETZKE, Miriam. Comportamento do Cliente. In: DIAS, Sergio Roberto et al (Org.). Gestão de Marketing. São Paulo: Saraiva, 2006. Cap. 3. p. 37-94.

BRETZKE, Miriam. Marketing Direto. In: DIAS, Sergio Roberto et al (Org.). Gestão de marketing. São Paulo: Saraiva, 2006. Cap. 15. p. 395-439.

CASAL JUNIOR, Marcello. Vendas online crescem 23\% no 10 trimestre, para R\$ 17 bilhões. 2019. Disponível em:

https://jconline.ne10.uol.com.br/canal/economia/nacional/noticia/2019/04/26/vendasonline-crescem-23_porcento-no-1-trimestre-para-r-17-bilhoes-377223.php. Acesso em: 26 maio 2019.

COSTA, Maria Cristina Castilho. Sociologia: introdução à ciência da sociedade. 3. ed. São Paulo: Moderna, 2005. 416 p.

CROCCO, Luciano et al. Marketing: perspectivas e tendências. São Paulo: Saraiva, 2006. 169 p. $4 \mathrm{v}$.

DINO. O crescimento da indústria de games no Brasil. 2018. Disponível em:

https://exame.abril.com.br/negocios/dino/o-crescimento-da-industria-de-games-nobrasil/. Acesso em: 10 out. 2019.

GIL, Antonio Carlos. Como elaborar projetos de pesquisa. 5. ed. São Paulo: Atlas, 2010. 184 p.

HOOLEY, Graham J.; SAUNDERS, John A.; PIERCY, Nigel F. Estratégia de marketing e posicionamento competitivo. 3. ed. São Paulo: Pearson Prentice Hall, 2005. 464 p. Tradução de: Robert Brian Taylor.

JUNQUEIRA, Daniel. Streaming de jogos é o futuro? Conheça os serviços de games na nuvem. 2019. Disponível em: https://olhardigital.com.br/games-econsoles/noticia/streaming-dejogos-e-o-futuro-conheca-os-servicos-de-games-nanuvem/

83898. Acesso em: 26 maio 2019.

KOTLER, Philip; ARMSTRONG, Gary. Princípios de marketing. 12. ed. São Paulo: Pearson Prentice Hall, 2007. 600 p. Tradução de: Cristina Yamagami.

LAKATOS, Eva Maria; MARCONI, Marina de Andrade. Fundamentos de metodologia científica. 8. ed. São Paulo: Atlas, 2017. 346 p.

LIMEIRA, Tânia Maria Vidigal. Fundamentos de Marketing. In: DIAS, Sergio Roberto et al (Org.). Gestão de marketing. São Paulo: Saraiva, 2006. Cap. 1. p. 1-15.

MALHOTRA, Naresh K. Basic marketing research: adecision-making approach. 3. ed. São Paulo: Pearson Prentice Hall, 2011. 491 p. Tradução: Opportunity Translations. 
MATTAR, Fauze Najib. Pesquisa de marketing: edição compacta. 5. ed. Rio de Janeiro: Elsevier, 2012. 317 p.

MELLO, André. Sete motivos para comprar um PC gamer em vez de um console. 2018. Disponível em: https://www.techtudo.com.br/listas/2018/12/setemotivos-para-comprar-umpc-gamer-em-vez-de-um-console.ghtml. Acesso em: 26 maio 2019.

NEWZOO. The Brazilian Gamer 2017. 2017. Disponível em: https://newzoo.com/insights/infographics/the-brazilian-gamer-2017/. Acesso em: 10 out. 2019.

RICCA NETO, Domingos. Administração e marketing para pequenas e médias empresas de varejo. São Paulo: Cla Cultural, 2005. 94 p.

ROCHA, Marcos et al (Org.). Marketing estratégico. São Paulo: Saraiva, 2015. 304 p.

SAKUDA, Luiz Ojima; FORTIM, Ivelise; HARRIS, Jonathan. Análise do Mercado Brasileiro. In: SAKUDA, Luiz Ojima; FORTIM, Ivelise (Org.). 2o Censo da Indústria Brasileira de Jogos Digitais. Brasília: Ministério da Cultura, 2018. p. 243-265.

SCUSSEL, Fernanda Bueno Cardoso. Diga-me quem és e te direi se me relacionarei com você: a influência da personalidade de marca com clientes no mercado de moda feminina de luxo. 2015. 185 f. Dissertação (Mestrado) Curso de Administração, Faculdade de Economia, Administração e Contabilidade - Face, Universidade de Brasília, Brasília, 2015.

SILVEIRA, Daniel. Número de desenvolvedores de games cresce $600 \%$ em 8 anos, diz associação. 2017. Disponível em: https://g1.globo.com/economia/negocios/noticia/numerode-desenvolvedores-degames-cresce-600-em-8-anos-diz-associacao.ghtml. Acesso em: 10 out. 2019.

SIOUX GROUP (São Paulo). 5a Pesquisa Game Brasil. 2018. Disponível em: https://www. pesquisagamebrasil.com.br/. Acesso em: 10 out. 2019.

SOUZA, Lucas Lopes Ferreira de; FREITAS, Ana Augusta Ferreira de. Consumer behavior of electronic games' players: a study on the intentions to play and to pay. Revista de Administração, São Paulo, v. 52, n. 4, p.419-430, out. 2017. Elsevier BV. Disponível em: http://dx.doi.org/10.1016/j.rausp.2017.08.004. Acesso em: 10 out. 2019.

VINHA, Felipe. O que é Steam? conheça a loja de jogos para PC da Valve. 2019. Disponível em: https://www.techtudo.com.br/noticias/2019/02/o-que-e-steamconheca-a-loja-de-jogos-parapc-da-valve.ghtml. Acesso em: 26 maio 2019.

ZIKMUND, William G. Essentials of marketing research. 2. ed. São Paulo: Pioneira Thomson Learning, 2006. 544 p. Tradução técnica: Cristina Bacellar. 